\title{
The Relationship between Brain-derived Neurotrophic Factor's Serum Level and Hospital Anxiety and Depression Scale-depression in Patients with Psoriasis Vulgaris
}

\author{
Elmeida Effendy ${ }^{1 *(D)}$, Muhammad Sjahrir ${ }^{2}$, Nurul Utami ${ }^{1}$ \\ ${ }^{1}$ Department of Psychiatry, Faculty of Medicine, Universitas Sumatera Utara, Medan, Indonesia; ${ }^{2}$ Department of Dermato- \\ Venerology, Faculty of Medicine, Universitas Sumatera Utara, Medan, Indonesia
}

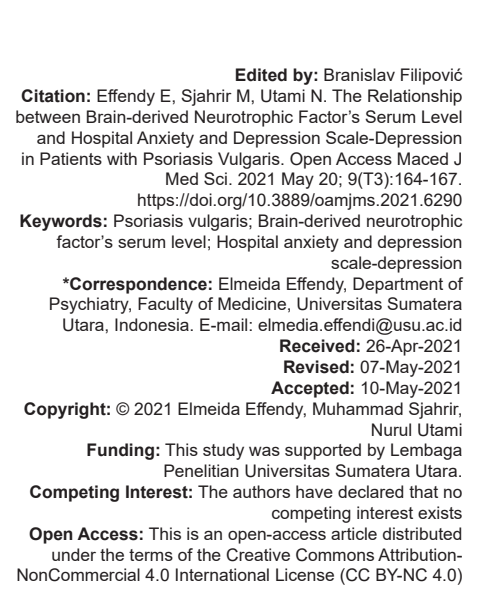

Abstract

BACKGROUND: Psoriasis vulgaris is a chronic inflammatory skin disorder that can lead to depression. The involvement of the nervous system in psoriasis was proved by the influence of brain-derived neurotrophic factor $(B D N F)$ in regulating corneocyte homeostasis. Low level of BDNF in patients with psoriasis result in transit amplifying subpopulation of basal keratinocytes not performing their function as inhibitors of keratinocyte proliferation, resulting in acceleration of keratinocyte proliferation. In depressed patients, it is known that levels of BDNF in the serum and hippocampus are low. BDNF level imbalance potentially affects the severity of psoriasis and depression.

METHODS: This is an analytical cross-sectional study. The measurement of BDNFs serum level was carried out in the Medan Private Laboratory using a human BDNF (R and $D \circledR$, USA) kit using the ELISA method. We use hospital anxiety and depression scale (HADS-D) questionnaire to assess depression symptoms.

RESULTS: The results of the Spearman correlation test for BDNFs serum level and HADS-D showed $p<0.05$, it can be concluded that there is a correlation between BDNFs serum level and HADS-D. The strength of the relationship between HADS-D and BDNFs serum level is -0.537 that shows moderate correlation $(r=0.4-<0.6)$. Relationship between HADS-D and BDNFs serum level is -0.537 that shows moderate correlation $(r=0.4-<0.6)$.

CONCLUSION: This study shows a moderate negative relationship between BDNFs serum level and the degree of symptoms of depression, which the lower level of BDNFs serum will increase the degree of depression symptoms.

\section{Introduction}

Psoriasis is a chronic inflammatory skin disease, with the presumption that genetic factors significantly affect the appearance of this disease [1]. The involvement of the nervous system in psoriasis was proved by the influence of brain-derived neurotrophic factor (BDNF) in regulating corneocyte homeostasis [2]. In addition to its role in keratinocytes, BDNF has also has role in depression. In depressed patients, it is known that level of BDNF in the serum and hippocampus is low [3], [4].

The prognosis of psoriasis vulgaris is unpredictable. Research that followed psoriasis patients for 21 years found that, as many as $71 \%$ of patients experienced persistent lesions, $13 \%$ of patients recovered completely and $16 \%$ of patients experienced intermittent symptoms [5].

Psychological and social pressures that can be experienced by psoriasis patients are stigma and shame which results in depression. Studies report that the prevalence of depression in psoriasis patients is
$10-62 \%$ [6]. A cross-sectional study found that $32 \%$ of people living with psoriasis were depressed from a total of 265 psoriasis patients [7].

Patients with psoriasis have a higher tendency to be depressed than leprosy, vitiligo, and lichen planus. Depression in patients with psoriasis affects treatment compliance so that if treatment is not overcome; treatment is impossible to achieve [6].

The chronic course of psoriasis and the drug that has not been found has the potential to cause depression. The meta-analysis study conducted by Dowlatshahi et al. found that people with psoriasis had a tendency to depression as much as $1 \frac{1}{2}$ times that of healthy individuals [8].

Study by Fortune said that psychological disorders that could occur in psoriasis patients were appearance problems being esthetic cause sufferers to become inferior, social rejection, feelings of guilt, shame, feeling empty, and sexual disturbances to disruption to work [9]. Psychological disorders in psoriasis can even lead to suicidal ideas.

Cooper-Patrick et al. said, the prevalence of suicide ideation in people with psoriasis is higher 
than other medical conditions or in the population as a whole [10].

Based on the explanation above, there is a link between psoriasis, BDNF, and depression, so we want to know for sure about the relationship between BDNFs serum level and depression's symptoms in patients with psoriasis vulgaris.

\section{Methods}

\section{Patient sample}

This study is an analytical cross-sectional, from May to July 2018, at outpatient clinic of Immunodermatology Division of Department DermatoVenereology, H. Adam Malik Hospital, Medan, Sumatera Utara, Indonesia. The subjects who participated were 46 people. Inclusion criteria in the study as follows: Patients who were diagnosed clinically as sufferers of psoriasis vulgaris, aged 20-65 years, willing to participate in research and sign informed consent. The exclusion criteria in this study were as follows: Patients with psoriasis vulgaris who were pregnant and breastfeeding, patients with psoriasis vulgaris who were using topical drugs to treat psoriasis vulgaris (topical corticosteroids, calcipotriol, tazarotene, and tar) at least 2 weeks before research and systemic (methotrexate, acitretin, cyclosporin, and corticosteroids) at least 6 weeks before the study, psoriasis vulgaris sufferers suffering from bipolar and schizophrenia disorders, and patients with psoriasis vulgaris using antidepressant drugs.

\section{Biological studies}

We measured BDNF serum level in Medan Private Laboratory using a Human BDNF kit ( $R$ \& $D^{\circledR}$, USA) and ELISA method. To assess depression symptoms we used hospital anxiety and depression scale (HADS-D) questionnaire.

\section{Statistical analysis}

The collected data are processed by hypothesis analysis method to determine the degree of closeness of the relationships between variables. Analysis is done using data processing software.

\section{Results}

\section{Process evaluation results and metrics}

The relationship between BDNF serum level and depressive symptoms was analyzed by Spearman correlation test. The result showed $p<0.05$ indicates a significant relationship.

The subjects in the study were 46 patients with psoriasis vulgaris who came to the dermatology venereology clinic.

The results showed that the mean BDNF levels in this study were $912.45 \pm 180.94 \mathrm{pg} / \mathrm{ml}$.

The results showed that the mean HADS-D score in this study was $11.22 \pm 2.52$.

The results show of the Spearman correlation test for BDNFs serum level and HADS-D obtained $p<0.05$ and concluded that there was a correlation between BDNFs serum level and HADS-D. The strength of the relationship between BDNFs serum level and HADS-D is $r=-0.537$.

\section{Discussion}

The subjects in the study included were appropriate based on inclusion and exclusion criteria. The subjects in the study were 46 patients with psoriasis vulgaris who came to the dermatology venereology clinic. Subjects with male and female sex were included in this study. Based on the level of education they are divided into three types, junior high school, senior high school and college.

Based on the duration of illness of patients with psoriasis vulgaris there are those $2-5$ years and over 5 years (Table 1).

In this study, it was found that the mean BDNF levels in this study were $912.45 \pm 180.94 \mathrm{pg} / \mathrm{ml}$ (Table 2). Research conducted by Narbutt et al. reported that the mean BDNF level in patients with psoriasis vulgaris was $14.35 \mathrm{ng} / \mathrm{ml}$. This mean did not differ significantly in patients with psoriasis vulgaris at $16.39 \mathrm{ng} / \mathrm{ml}$ $(p=0.121)[11]$.

A study from Brunoni et al. reported that the mean BDNF levels of patients with psoriasis vulgaris $(3406 \pm 3124 \mathrm{pg} / \mathrm{ml})$ were more significantly lower ( $p<0.01)$ compared to healthy controls (5947 \pm $6300 \mathrm{pg} / \mathrm{ml}$ ) [2].

This difference shows an interesting phenomenon for further research to prove whether BDNF has a very important role in the pathogenesis of psoriasis.

Before correlative testing at baseline data, the data normality test was performed which the HADS-D variable was tested for normalization using the ShapiroWilk test because the number of samples was $<50$ (Table 3), and it was found that the HADS-D score, the variable was not normally distributed so that correlative baseline data using the Spearman correlation test. The results of the Spearman correlation test for 
Table 1: Demographic characteristics

\begin{tabular}{|c|c|c|}
\hline Variable & $\mathrm{n}$ & $\%$ \\
\hline \multicolumn{3}{|l|}{ Age (years) } \\
\hline $20-29$ & 6 & 13 \\
\hline $30-39$ & 14 & 30.4 \\
\hline $40-49$ & 14 & 30.4 \\
\hline $50-59$ & 10 & 21.7 \\
\hline$\geq 60$ & 2 & 4.3 \\
\hline \multicolumn{3}{|l|}{ Gender } \\
\hline Male & 24 & 52.2 \\
\hline Female & 22 & 47.8 \\
\hline \multicolumn{3}{|l|}{ Education } \\
\hline $\begin{array}{l}\text { Junior high } \\
\text { school }\end{array}$ & 4 & 8.7 \\
\hline Senior high & 12 & 26.1 \\
\hline $\begin{array}{l}\text { school } \\
\text { College }\end{array}$ & 30 & 65.2 \\
\hline \multicolumn{3}{|c|}{ Duration of illness } \\
\hline $2-5$ years & 12 & 26.1 \\
\hline$>5$ years & 34 & 73.9 \\
\hline
\end{tabular}

BDNFs serum level and HADS-D obtained $p<0.05$ and concluded that there was a correlation between BDNFs serum level and HADS-D. The strength of the relationship between BDNFs serum level and HADS-D, $r=-0.537$ shows moderate correlation $(r=0.4-<0.6)$.

Table 2: Brain-derived neurotrophic factor serum level

\begin{tabular}{lll}
\hline Subject $(\mathrm{n})$ & Mean \pm SD & Min-Max \\
\hline 46 & $912.45 \pm 180.94$ & $575.06-1227.62$ \\
\hline
\end{tabular}

Fatty et al. reported that there was lower BDNFs serum level in both groups of psoriasis (without depression $25.2 \pm 6.5$; with depression $16.9 \pm 2.5)$ compared to the healthy control group $(26.5 \pm 3.6)$. BDNFs serum level was significantly lower in psoriasis vulgaris patients who suffered from depression compared to psoriasis patients who did not suffer from depression (mean difference 8.3; $p<0.001)$. BDNFs serum level was also significantly lower in psoriasis vulgaris patients who were depressed [12]. The mean of BDNFs serum level was significantly lower $(p<0.01)$ in the group of psoriasis patients who suffered from depression $(16.9 \pm 2.5)$ compared to depressed patients without psoriasis vulgaris $(21.5 \pm 5.8)$ [13].

Table 3: Hospital anxiety and depression scale-depression score

\begin{tabular}{lll}
\hline Subject $(\mathrm{n})$ & Mean \pm SD & Min-Max \\
\hline 46 & $11.22 \pm 2.52$ & $8-15$
\end{tabular}

\begin{tabular}{lll} 
Subject $(\mathrm{n})$ & Mean \pm SD & Min-Max \\
\hline 46 & $11.22 \pm 2.52$ & $8-15$ \\
\hline
\end{tabular}

Korkoliakou et al. reported that there was no significant difference between depression with psoriasis vulgaris and healthy controls $(p=0.28)$ using the HADS depression measuring instrument [14].

Based on $\mathrm{Yu}$ and Chen study, the role of BDNF in the occurrence of depression is proved by four things. First, depression causes a decrease in BDNF levels in the hippocampus and prefrontal cortex. Second, depression triggers dendritic nerve atrophy in the hippocampus and prefrontal cortex. Third, there is evidence of increased levels of BDNF in the hippocampus and prefrontal cortex after antidepressant administration. Fourth, BDNF levels are increased in the amygdala and areas of neural accumbent that facilitates symptoms of depression [15].

This is in accordance with studies conducted based on the results from Table 4 which explains the strength of the relationship in patients with psoriasis which is shown by the lower serum BDNF levels, it will improve depressive symptoms as indicated by the results of the HADS-D score.

Table 4: Correlation between BDNF serum level and HADS-D score

\begin{tabular}{lc}
\hline Serum levels of BDNF & \\
\hline Score HADS-D & $\mathrm{r}=-0.537$ \\
& $\mathrm{p}=0.008$ \\
$\mathrm{n}=46$ & \\
& \\
"Spearman's correlation test. BDNF: Brain-derived neurotrophic factor, HADS-D: Hospital anxiety and \\
depression scale-depression.
\end{tabular}

depression scale-depression.

\section{Conclusions}

This study obtained the correlation coefficient $(r=-0.537)$ with medium strength and significance value $(p=0.008)$. This shows a medium negative correlation between BDNFs serum level and the degree of depression's symptoms, which the lower BDNFs serum level will increase the degree of symptoms of depression.

\section{Authors' Contributions}

All authors contributed to the study and writing of the article. All authors have read and approved the final version of the manuscript. EE and MS contribute in collecting and analyzed data, EE and NU contribute in make the manuscript.

\section{Acknowledgments}

This study was supported by installation of the Department of Dermato-Venerology, Faculty of Medicine, USU. The author is very grateful to the resident of the Department of Psychiatry Faculty of Medicine Universitas Sumatera Utara who expertise and help to conduct this study. This study supported by Lembaga Penelitian Universitas Sumatera Utara.

\section{Ethics Approval and Consent to Participate}

This study has obtained ethical clearance from the ethical commission of the Faculty of Medicine, 
Universitas Sumatera Utara, with number 609/TGL/ KEPK FK USU - RSUP HAM/2016.

\section{Availability of Data and Materials}

That data will not be shared, the data required to reproduce these findings cannot be shared at this time due to ethical reason, technical, or time limitations.

\section{References}

1. Gudjonsson JE, Elder JT. Psoriasis. In: Goldsmith LA, Katz SI, Gilchrest BA, Paller AS, Leffell DJ, Wolff K, editors. Fitzpatrick's Dermatology in General Medicine. $8^{\text {th }}$ ed. New York: Mcgraw Hill Companies; 2012. p. 197-231. https://doi. org/10.1111/j.1524-4725.2008.34211.x

2. Brunoni AR, Lotufo PA, Sabbag C, Goulart AC, Santos IS, Bensenor IM. Decreased brain-derived neurotrophic factor plasma levels in psoriasis patients. Braz $\mathrm{J}$ Med Biol Res. 2015;48(8):711-4. https://doi.org/10.1590/1414-431x20154574 PMid:26200230

3. Karege F, Perret G, Bondolfi G. Decreased serum brainderived neurotrophic factor levels in major depressed patients. Psychiatry Res. 2002;109(2):143-8. https://doi.org/10.1016/ s0165-1781(02)00005-7 PMid:11927139

4. Sen S, Duman R, Sanacora G. Serum brain-derived neurotrophic factor, depression, and antidepressant medications: Metaanalyses and implications. Biol Psychiatry. 2008;64(6):527-32. https://doi.org/10.1016/j.biopsych.2008.05.005 PMid:18571629

5. Fry L. An Atlas of Psoriasis. Carnforth: Parthenon Publishing; 1992.

6. Meffert J. Psoriasis. USA; 2015. Available from: http://www. emedicine.medscape.com/article/943419-overview. [Last accessed on 2016 July 03].
7. Schmitt J, Ford DE. Understanding the relationship between obejctive disease severity, psoriatic symptoms, illness-related stress, health-related quality of life and depressive symptoms in patients with psoriasis a structural equations modeling approach. Gen Hosp Psychiatry. 2007;29(2):134-40. https://doi. org/10.1016/j.genhosppsych.2006.12.004

PMid:17336662

8. Dowlatshahi EA, Wakkee M, Arends LR, Nijsten T. The prevalence and odds of depressive symptoms and clinical depression in psoriasis patients: A systemic review and metaanalysis. J Investig Dermatol. 2014;134(6):1542-51. https://doi. org/10.1038/jid.2013.508

PMid:24284419

9. Fortune DG. Psychologic factors in psoriasis: Consequences, mechanisms, and interventions. Dermatol Clin. 2005;23(4):681-94. PMid:16112445

10. Cooper-Patrick L, Crum RM, Ford DE. Identifying suicidal ideation in general medical patients. JAMA. 1994;272(22):1757-62. https://doi.org/10.1001/ jama.1994.03520220051030 PMid:7966924

11. Narbutt J, Olejniczak I, Sztychny SD, Jedrzejowska SA Kwiatkowska SI, Hawro T, et al. Narrow band ultraviolet B irradiations cause alteration in interleukin-31 serum level in psoriatic patients. Arch Dermatol Res. 2013;305(3):191-5. https://doi.org/10.1007/s00403-012-1293-6 PMid:23108364

12. Bath KG, Schilit A, Lee FS. Stress effects on BDNF expression: Effects of age, sex, and form of stress. Neuroscience. 2013;239:149-56. https://doi.org/10.1016/j. neuroscience.2013.01.074 PMid:23402850

13. Fatty H, Tawfik AA, Madbouly N. Evaluation of serum brainderived neurotrophic factor in assessing the association between psoriasis and depression. J Egypt Women Dermatol. 2015;12:186-90.

14. Korkoliakou P, Christodoulou C, Kouris A, Porsche E, Efstathiou V, Kaloudi E, et al. Alexithymia, anxiety and depression in patients with psoriasis: A case-control study. Ann Gen Psychiatry. 2014;13(1):38. https://doi.org/10.1186/s12991-014-0038-7 PMid:25520742

15. Yu $\mathrm{H}, \mathrm{Chen} \mathrm{Z}$. The role of BDNF in depression based on its location in theneural circuitry. Acta Pharmacol. 2011;32(1):3-11. PMid:21131999 